7 he infusion of capital into biotechnology over the past twelve months is a welcome sign for anybody involved in this area of $\mathrm{R} \& \mathrm{D}$. As this month's feature on new sources of international finance indicates, there is renewed confidence in the profitability of biotech research; in the U.S., at least, this is coupled with a strengthening economy and an improved interest climate.

These boom days for biotech investment differ from the time when the first biotech companies emerged. The most distinguishing characteristic is maturity: most of the companies that recently completed public stock offerings are further down the path of product development than their predecessors. Another sign of maturity is the large investment pool being channeled through the R\&D limited partnership vehicle. With a few exceptions, this money has flowed into relatively well-established companies with the talent and experience to focus their research and engage in clinical testing of products.

Healthy as it appears, this new climate could sour because of purely economic factors. The destabilization of the world economy through default on loans by developing countries or the tag team of inflation and recession that plagues many developed countries are obvious contributing factors.

Poor management of this sudden infusion of capital could breed a disaster that wouldn't manifest itself for another three to five years. At that time an array of new products will be available that will need vast expenditures for testing and marketing. There will always be a temptation to underestimate these expenses, invest heavily in the research end of the stream, and hope that revenues from other products will pay for the testing and marketing of newer products. Either managers of cash-bloated mutual funds with little understanding of how to invest in the technology or corporate financial officers with limited experience in technology management could create a situation in which funds are not available to fully commercialize these products. In this event, medium-sized firms tend to be squeezed out of the market by large multinationals with established marketing operations and the capital to purchase rights to products from the strugglers. This trend could breed sufficient insecurity among biotech investors to lower stock prices and diminish investment.

Another danger confronting biotechnology is the dilution of profit by financing schemes designed to counter the inherent riskiness of $\mathrm{R} \& \mathrm{D}$ projects. For example, the currently popular R\&D limited partnerships could prove to be the devil's bargain for many companies. Although they minimize the company's liability by involving outside investors, these financing schemes diminish product revenues through royalty payments to limited partners. Their key value for specialty firms-their ability to ensure financial survival while minimizing risk of the company's capital-will be compensated by a loss of corporate growth in the future.

The balance between risk and payoff on the financial side will be paralleled by the precarious balance set between exploratory research and product development by corporate planners. If specialty firms can stake a claim on the most advanced research needed to compete with large multinationals, they will never escape the spiral of increased risk that accompanies long-term basic research. How far can any company afford to explore? How far is a firm compelled to explore to assure a position in new markets? Unlike the large multinationals, which can balance their risks with products that are not subject to technological displacement, the values of specialty companies are destined to depend upon the rate of overall innovation in biotechnology and the confidence of investors in this area. Even in their mature years, companies that specialize in innovative products or processes are unlikely to be relatively stable investments.

The new wave of international capital that biotech now enjoys will test the wits of marketing and finance officers as the technology matures. These experts, who currently stand in the shadows of the flashy science that characterizes much of biotechnology, may prove to be the true heroes in this field. The abilities of these managers to balance risks in harmony with corporate technology planners will determine how much of today's ambitious research will actually benefit society.

-Christopher G. Edwards

\section{GOOD NEWS FROM NSF FOR RESEARCH}

7 he National Science Foundation (NSF) enters fiscal 1 year 1984 with a healthy 21 percent budget increase. This increase, which will provide a $\$ 31.4$ million boost to the current bioscience research budget of approximately $\$ 145.5$ million, will certainly benefit biotechnology. NSF officials estimate that a significant increase in funding will be allocated to research on plants over the fiscal year, a welcome acknowledgment of the importance of this work in agriculture. NSF also recognizes the need for advanced instrumentation for research, and has allocated approximately 11 percent of the biosciences budget for this purpose.

NSF officials project increases in funding for chemical engineering, particularly in allocations for engineering aspects of biotechnology. All of these estimates reflect a desire on the part of NSF to fund all aspects of biotech, from molecular research to scale up and production.

Increased funding for studies of scale up and production problems will be especially welcomed. This could counter the current technology gap in this area, a result of the time it takes to test some of these systems, the proprietary status of industrial activity, and the lack of academic research on production compared with the microbial side of biotechnology. The NSF now needs strong proposals for developing projects with wide industrial impact. Increased funding of academic projects with industrial implications could help bring about a further integration of industry with the university.

-Christopher G. Edwards 